\title{
RE-THINKING SECURITY - CORONAVIRUS PANDEMIC IMPACT ON SECURITY AGENDA
}

\author{
Aleksandar Pavleski ${ }^{24}$ \\ Ss. Cyril and Methodius University, Faculty of Philosophy, Institute of Security, Defence and \\ Peace
}

\begin{abstract}
New security risks and threats initiate new thinking about security as well as about the necessity of continuous updating the security agenda itself. The world is confronting a new common threat today that it must defeat collectively by applying new approaches and methods. Actually, the coronavirus pandemic has opened a dilemma about the new security understanding as well as about re-thinking International Security Agenda challenges. The emergence of new enemies and rapidly changing of the hierarchy of global security threats, initiates a need for a fundamental change in national and international security priorities. Hence, the possibility for revising of the security agenda framework and understandings is opened. Therefore, the paper analyzes whether and how the current security agenda framework offers opportunities and responses to the new pandemic environment as well as whether and how Coronavirus pandemic changes thinking on security.
\end{abstract}

Key words: security, risks, threats, Covid-19 pandemic

\section{Introduction}

The security agenda development confirms that security is a variable category. What makes people save of feel save depends upon two basic phenomena, each of which can assume different values, or can vary. The most obvious source of challenge to our security is factors that threaten the things that people value. The most objective in this regard are physical threats, such as the danger of destruction from the eventual use of weapons. This creates the physical dimension of security. On other hand, psychological dimension or psychological threats, what makes people feel secure or insecure, are often less tangible and are subject to individual interpretation. It means that different people could feel secure or insecure in the same situation.

The Covid19 pandemic has raised a dilemma about what it means to be secure and how policy makers determine threats to security. The reason regarding this dilemma may be sought in the fact that the very nature and consequences of the Covid-19 pandemic go beyond the framework of the traditional and the new security agenda as well.Threats to people's survival and livelihood brought on by Covid-19 illustrate how the pandemic is much more than a health crisis.Despite the large loss of human lives, Coronavirus pandemic has also resulted in a staggering rise in unemployment and a multi-pronged global economic

${ }^{24}$ Contact address: pavleski@fzf.ukim.edu.mk 
crisis. Moreover, it has exposed fundamental weaknesses in the delivery of social services, as well as systems of social protection and preparedness.

Regarding to the research focus in this paper, it could be noted that the Covid-19 pandemic has pointed out that health needs to be dealt with as a global security issue. In this context, the question arises about the necessity of security agenda expanding with the human health as a reference object.Still, it doesn't mean that human being as a reference object has no place, above all in, especially in the new security agenda. The United Nations Development Programme's (UNDP) Human Development Report published in 1994 is considered the starting point for human security concept development (UN: Human Development Report (1994).

Further, there is no doubt that the political, economic, social and environmental dimensions of security enable the creation of a broader security vision and meaning within the new security agenda.There are included several important aspects of human life and dignity in such a broader security perception within all the previously indicated security dimensions.

Still in the other hand, the Coronavirus pandemic has initiated a necessity of paying more attention and implementing broader approach to the human health and life. Actually, Coronavirus pandemic has initiated a resurgence of interest in human security as acceptable framework for placing sustained improvements in all dimensions of people's lives. Moreover, the pandemic has shown that almost none of the sectors of the extended security concept is immune to its dynamics as well.

Hence the dilemma of whether and what impact the Coronavirus pandemic will initiate about the re-thinking of security as well as ina resurgence importance of human security issue in security agenda.

\section{Understanding security - theoretical aspects}

There isn't acceptable universal definition about the security among the scholars, what confirms that it is a variable category. Actually, the meaning of security is dependent on the context in which it is being used and by whom it is being used as well.

In terms of analysis focus, the different security conceptions are generally divided into two theoretical approaches in this paper. Actually through the prism of the traditional and critical theoretical approach, the evolution and updating of the security concept and the security agenda itself are analyzed. Such an analysis provides a clearer picture of whether and how certain threats affect the security understanding as well as the expansion of the security agenda itself.

It's no doubt that there exist various types of threats that a states and peoples as well faces in today's world. Such as various types of threats affect a security dilemma in several ways.

The risk of war and violent conflict as well, has long been at the centre of reflection on security and security studies. Traditionally, this has been translated into the study of war or legally recognized armed conflict between organized groups (Kraues, 2010).

In this regard, the security debate has for too long focused on traditional or military threats towards the state and the "softer" issues such as environment, trade, transnational crime, human security, etc. have not been seen as potential security threats (Waltz, 1979). One important reason for this is that traditionally, security threats could, by definition, 
only be directed towards "the state and the state is and should be about security, with the emphasis on military and political security (Buzan at all., 1998). Actually, security is traditionally understood as 'freedom of threat'.

Thus an issue or event would only be classified a security threat if the survival of the state as an entity was at risk. Moreover,traditional security threats arise out of conventional international issues and disputes that often result in a full-scale war or conventional conflicts among the involved parties.Therefore, the state is a primary referent object in traditional security agenda. It is also the central object through whom the dynamics in the security sphere are understood.The human security or individual security is neglected in relation to the state security in those dynamics. In such a traditional approach, security is equated with military security, ie: 1)security threats stem from the war; 2 ) war is the result of the anarchic international relations; and 3) threats can be deterred by establishing a system of power balance or by nuclear intimidation (Buzan at all., 1998).

Still related to above mentioned, the question arises whether the military threats are the only dangers that states face, or does the military power is the only source of states security?

The realistic understanding and thought about international relations and security as well correlates with the indicated security perception of the traditional approach. Actually, realists feel that states must be self-reliant as well as that there is a minimal chance of cooperation between states in anarchic world. Still, they cannot explain changes to the political landscape and cannot explain the rise of international organizations. On other hand, the end of bipolarity has clearly demonstrated, through substantial changes to the foreign and security policies of most states, that international structures make a huge difference to the security environment of actors.

Such a traditional view of security has significantly changed under the globalization process influence and the number of international organizations that carry significant weight as well.Actually, by the end of the last century, a new view passed over previously security agenda in general, provoked by the exhaustion and decline of the previously bi-polar security complex. As a result, traditional security approach was regarded as inadequate to the task of explaining for a new landscape of security issues and actors and a new set of principles began to emerge.

Actually, the efforts to place non-military issues on the security agenda created a debate of its own. This debate grew out of the dissatisfaction with the intense narrowing of the field of security studies imposed by the military and nuclear obsession of the Cold War. Such a dissatisfaction was stimulated first by the rise of the economic and environmental agendas in international relations and later by the rise of concerns with identity issues and transnational crime (Buzan at all., 1998).

By promoting a decentralized approach to security, critical security studies support the expansion and deepening of the security concept. A security expansion refers to security understanding not only through the military sector, but also by incorporating the political, economic, social and environmental dimensions of security.lt means that security is affected by factors in all of those sectors. On the other hand, the deepening of security refers to the units of analysis and the introduction of new security reference actors or objects (besides the state) (Buzan at all., 1998). Specifically, in addition to the 
state, human, regions and the international system are also added as important reference objects in these sense.

It means that security is Understanding the security dynamics and the nature of security threats in each of these five sectors is at the heart of the wider security agenda. Therefore, generally speaking, military concerns the two-level interplay of the armed offensive and defensive capabilities of states. Political security concerns the organizational stability of states, systems of government and the ideologies that give them legitimacy. Economic security concerns access to the resources, finance and markets necessary to sustain acceptable levels of welfare and state power while societal security concerns the sustainability, within acceptable conditions for evolution, of traditional patterns of language, culture and religious and national identity and custom. Environmental security concerns the maintenance of the local and the planetary biosphere as the essential support system on which all other human enterprises depend (Buzan, 1991).

Having in mind the content of the indicated wider security agenda on the one hand and the characteristics of the contemporary security environment on the other hand, the question of its applicability inevitably arises today. Actually, the nature of security dynamics today, increasingly emphasizes the importance of the so-called cyber security, food security, financial security, energy security, biosecurity and pandemic security as well. Regarding to the indicated types of security, it can be emphasized that the state and individuals as reference objects of security, have equal importance, i.e., that they are equally vulnerable to new security threats. This initiates a necessity for a better and even broader understanding of security, or as Marc A. Levy, pointed out that "what we need is not a new way of thinking, but a better old thinking of security" (Levy, 1995).

\section{Securitization of the COVID-19 pandemic}

In theoretical point of view, securitization theory offers an acceptable framework for analyzing whether and how Covid-19pandemic can be perceived as a security issue.

Thesecuritization theory that grew out of a research group at the Copenhagen Peace Research Institute in the 1980s, has a significant impact on the expansion of the security concept and thus the security agenda itself. Seen from the point of view of this theoretical approach security signifies a situation marked by the presence of a (security) problem and some measure against it. Oppositely, insecurity is the situation with a security problem but with no measure against it.

In this regard, Ole Wæver pointed out that each question/issue can be asked as: non-politicized - the state doesn't deal with the issue and it is not a part of the public debate; politicized - the issue is part of a public policy and the government decides and provides certain means to address it; and securitized - the issue is presented as an existential threat and it should be addressed as a priority issue which opened a necessity of extraordinary measures in dealing with it (Wæver, 0. at. Al., 1992). It means that securitization process is determined by presence of an issue that is so urgent and existential, so it is important that it should be dealt with decisively by top leaders prior to other issues.

Regarding to the above mentioned, it is no doubt that Covid-19 can be analyzed as a securitization issue. Actually, since the World Health Organization (WHO) declared a pandemic with the new coronavirus Covid-19on March 11, 2020, due to the fact that 
the virus has spread to several continents ${ }^{25}$, a strong and clear message was sent to all countries in the world that the situation with Covid-19 is extremely serious and that every country, in accordance with its set-up and health system, must begin to prepare (including use of extraordinary measures) for dealing with the crisis. It could be noted that an urgency of their application initiated the Covid-19 issue to being posed as an existential threat. This could be also analysed as speech act approach from WHO about the urgent and existential nature of Covid-19, that has been accepted by the political elites as well.

In this regard, it should be noted that securitization theory is a self-proclaimed 'speech act theory' of security that focuses on the means by which security issues are constructed through language. According to the theory, a given object becomes securitized by virtue of the pronouncement of a securitizing actor, appropriately positioned, permitting it to be shifted from the order of ordinary politics to one kind or another of exceptional politics(Burgess, 2010).

Securitization, as a 'speech act' refers to the process, whereby an issue is presented as an existential threat, requiring emergency measures and justifying actions outside the normal bounds of political procedure.

It means that securitization requires, among other things, the invocation of an existential threat to a particular referent object. Still, a discourse that takes the form of presenting something as an existential threat to a referent object doesn't by itself create securitization - it is a securitizing move. The issue could be securitized only if and when the audience accepts it as such (Wæver, 0. at. Al., 1992).

Related to the above mentioned, it should be noted that there are four types of units/levels involved in security analysis of securitization approach. Such are: referent object, things that are seen to be existentially threatened and that have a legitimate claim to survival; securitization actor, actors who securitize issues by declaring something referent object - existentially threatened; functional actors: actors who affect the dynamics of a sector and actor who significantly influences decisions in the field of security; a public/ audience that needs to be convinced and accept the necessity of securitizing a particular issue(Buzan, 1998).

In this regard, Covid-19 analysis as a securitization issue, presents that the human individuals are main referent object. It is quite clear that the human health and lives are directly exposed to the impact and implications ofCovid-19. From mortality aspect, as of April 26, 2021, 3,111,247 deaths have been attributed to Covid-19.26

In the other hand, almost all social life spheres, both locally, regionally and globally as well, have been hit simultaneously by the implications and measures in dealing with the Covid-19 pandemic. In this regard, it could be talk about a multitude of indirect reference objects in almost all sectors of the above analysed extended security concept.

Actually, the pandemic has paralyzed and transformed a world in a very short time like no other danger/threat before. In addition to endangering the individual security of citizens, reactions and measures that have been introduced in almost all countries by their

25 The World Health Organization is a specialized agency of the UN and a coordinating body for global public health. It was founded in 1948 in Geneva, Switzerland.

${ }^{26}$ This information comes from the Coronavirus COVID-19 Global Cases map developed by the Johns Hopkins Center for Systems Science and Engineering. 
restrictive nature have negatively affected the level of human being rights and freedoms, which multiplied a multifaceted sense of insecurity.

Regarding the question about the securitizing actor, it is characteristic that the analysis points out about the approaches of two securitizing actors.The first one is the World Health Organization, which declared the Covid-19 pandemic, while the second one is made up of the political elites who have further alerted the public about the threats of this pandemic.

Actually, such an approach stems from the political responsibility of the political elites in recognizing and dealing with specific problems, as well as in managing them. The political agenda creates public awareness about the problem and provides common tools for solving it (Georgieva, 2009).

From the point of view of the functional actors, the analysis has also presents a wide range of direct and indirect functional actors that impact a dynamics associated with pandemic management. However, the most prominent functional actors are certainlythe pharmaceutical industry and the medical staff directly involved in dealing with Covid-19 implications and consequences for human health. The pandemic management process is directly dependent by the activities of the indicated functional actors. Still, the activities of all other subjects of social life, starting from the individuals themselves to the economic operators and political elites as well, have also a significant impact on the dynamics of the pandemic management process.

As a result of all the above mentioned, there is no doubt that the Covid-19 pandemic can be analysed as a security issue, especially from the aspect of the analytical framework of the theory of securitization. In this regard, the analysis points out that the Covid-19 became a securitized issue that needs to be addressed with a number of urgent measures that should be accepted by the general public as well. Compared to other contemporary security risks and threats, the pandemic highlighted the need for a new and broader approach in securing and ensuring human life and health.

Moreover, alongside the health risks associated with the virus, as most governments focus on the research and development of a safe vaccine, the security risks are also becoming more important with each passing day. There are restrictions on fundamental freedoms such the freedom of movement and assembly. In other side, the transportation industry alongside others has been severely affected, affecting the national economy. Millions have lost their employment and means of livelihood. Fear and panic have spread among the public at large.

As a result, it could be noted that while the Covid-19 pandemic is spreading chaos, non-traditional security issues are gaining importance and may directly or indirectly threaten the survival of states.Therefore, it is extremely important for all governments to reshape their policy processes to curtail the social, economic, political, diplomatic and human security risks associated with the Covid-19 pandemic.

\section{Conclusion}

The changed international security environment has resulted in a need for broader non-proliferation and disarmament activities that focus more on concerns such as the risks posed by bioterrorism and outbreaks of infectious diseases. Covid-19 pandemic exposed all the shortcomings and vulnerabilities of global and national societies as well. 
The characteristics and consequences of Covid-19, have initiated the emergence of specific security challenges and risks with the combination of which today, modern society has not faced before. Actually, in security aspect, the Covid-19 pandemic has shown that despite the advanced technological and scientific development, today's modern society is still seriously vulnerable to risks and threats of a non-military nature.

Arguments linking Covid-19 pandemic and security include that the social, economic and political stability of communities (and even entire states) could be undermined in the long run by a large disease burden. The analyse above highlighted that the security dimension of the pandemic is plain, it can undermine economic growth, exacerbate social tensions diminish military preparedness, create a huge social welfare cost and further weaken already beleaguered states as well.

All the indicated security aspects related to the Covid-19 pandemic emphasizes a necessity of re-thinking or of better thinking about the security concept by increasing the importance of non-military aspects and non-traditional approaches and responses in preventing and dealing with contemporary security threats and risks. Moreover, it is essential for states to counter non-traditional security threats because they can potentially reduce national resilience of states to prosper. The consequences of these threats could be more damaging for developing world, where there is population density, lack of medical facilities and most importantly economic vulnerability of the state to handle such threats for a prolonged period of time. As a result of all above mentioned, it is no doubt that pandemic security should be part of the contemporary security agenda.

\section{References}

1. Burgess, J. P. (2010): The Routledge Handbook of new Security Studies. Routledge Handbooks.

2. Buzan, B. (1991): People, States and Fear: An Agenda for International Security Studies in the Post-Cold War Era, 2nd ed. Boulder: Harvester Wheatsheaf.

3. Buzan, B. (1998): Security - A New framework for analysis. Boulder C0: Lynne Rienner.

4. Georgieva, L. (2009): Risk Management. Faculty of Philosophy, Skopje.

5. Kraues, K. (2010): Instruments of Insecurity. The Routledge Handbook of new Security Studies. Routledge Handbooks.

6. Levy, A.M. (1995): Is the environment a national security issue? International Security, 20(2).

7. UN: Human Development Report (1994). Available at>

8. http://hdr.undp.org/sites/default/files/reports/255/hdr_1994_en_complete_ nostats.pdf

9. Waltz, K. (1979): Theory of International Politics. Reading, Mass: Addison-Wesley. 
10. Wæver, 0. (1997): Concept of Security. Institute of Political Science, Copenhagen University.

11. Wæver, 0. at. Al. (1992): Identity, Migration and the New Security Agenda in Europe, Pinter Pub. London.

12. World Health Organization: Official Coronavirus Updates. Available at> https:// www.who.int/emergencies/diseases/novel-coronavirus-2019? gclid=CjwKCAjw49 qKBhAoEiwAHQVTowRXMIQIrI-SDLpGeBDu5RSz-BnxqBmna5NdMxPdLn3pqPs6 yEnw5hoCgf4QAvD_BwE 